Article

\title{
Integrating Risk Assessment into Spatial Planning: RiskOTe Decision Support System
}

\author{
Nelson Mileu * (iD) and Margarida Queirós \\ Institute of Geography and Spatial Planning, Universidade de Lisboa, 1600-276 Lisbon, Portugal; \\ margaridav@campus.ul.pt \\ * Correspondence: nmileu@campus.ul.pt; Tel.: +351-21-044-30-00
}

Received: 11 April 2018; Accepted: 9 May 2018; Published: 11 May 2018

\begin{abstract}
The way in which risk maps are used in decision support processes for spatial planning at local scale is critical to helping decision makers in the definition of a prevention strategy to minimize risks. This paper presents a spatial decision support system that is developed to assist spatial planning by integrating the risk management component at municipal level. For the development of the RiskOTe tool, a semi-quantitative risk assessment model was used that assumes risk management to be comprehensive with respect to the type of hazard, vulnerability and risk minimization measures. In this paper, the components for the development of the spatial decision support system are identified, described and implemented using the municipality of Oeiras, in Portugal, as case study. The use of the system allowed the generation of multiple scenarios and outcomes. The results demonstrate that decision-making on the transformation of land uses by integrating risk analysis can be supported on a solid basis of information obtained from a spatial decision support system.
\end{abstract}

Keywords: decision support system; spatial planning; risk assessment; scenarios; Web GIS

\section{Introduction}

Model-based Decision Support Systems (DSSs) have been used for many years and in different domains. In the domain of disaster risk reduction, Newman et al. [1] states that the development and use of decision support systems is increasingly important, mainly because natural hazards are having a significant impact on communities and economies; losses due to natural disasters are expected to increase into the future; risk reduction is broadly recognized as being more effective than response and recovery and risk reduction and residual risk affect communities and the natural environment in multiple ways, with complexity and uncertainty in causal processes driving hazard impacts.

Risk mapping is often referred to as an essential tool for reducing the risks of natural and technological hazards [2,3]. However, the way in which risk maps are created and used in decision support processes for spatial planning is an issue that is poorly explored, but one that is highly relevant for regional development and spatial planning [4] since is broadly recognized as being more effective in risk reduction than response or recovery [5-7]. This paper presents RiskOTe, a spatial decision support system, that is designed to support spatial planning while integrating the concepts associated with risk analysis and risk governance.

The different definitions of what is a "decision support system" follow the evolution of recent decades and reflect several perspectives. Recent definitions of a spatial decision support system (SDSS) present it as a combination of Geographic Information System (GIS) functionalities, remote sensing techniques, mathematical models and other decision support functionalities [8,9].

The initial development of decision support systems in risk management is attributed to Newman et al. [10], Belardo et al. [11], Belardo et al. [12] and Wallace and Debalogh [13]. In a more recent work on the use of decision support systems in disaster management, Cioca and Cioca [14] present 
a brief history of decision support systems, definitions, characteristics, functions, classifications and the advantages and limitations associated with the use of decision support systems that are used in disaster management. Considering the most recent works in the body of literature on decision support systems in risk management [15], it is possible to verify that it is a recurring theme which is used on several hazards and for different purposes [16].

The first document that relates spatial planning with risk analysis in the European Union was the European Spatial Development Perspective ([17], p.32) where it is stressed the role of spatial planning at suitable government and administrative levels in the protection of humans and resources against natural disasters. Greiving et al. [5] revealed that in Europe the role of spatial planning in risk assessment and management show many ways and has been overestimated. The application of SDSS in risk management as applied to the context of spatial planning in Europe is also scarce, and the system which was developed under the ARMONIA project is an example of integration risk analysis into spatial planning. The overall aim of the EU-funded research project "Applied multi Risk Mapping of Natural Hazards for Impact Assessment" (ARMONIA), was to develop a new approach to producing integrated multi-risk maps in order to achieve more effective spatial planning procedures in areas within Europe that are prone to natural disasters [18]. In this context, Menoni et al. [19] developed a framework and decision support tool to ensure that planning decisions are fully informed about the multiple hazards affecting particular areas of land, the vulnerability of different land uses and populations (taking account of the main social factors) and the options that are available to mitigate the risks. Regarding the Portuguese case study, the integration of risk analysis into spatial planning is supported by the legal requirement that establish for the municipalities, the obligation to include risk maps in Municipal Master Plans (MMP) according the Legal System of Territorial Management Instruments (Decree-Law 80/2015, of May 14). This Decree-Law (article 13) recommends the delimitation of hazardous and risk areas, the identification of vulnerable elements for each type of risk, and the establishment of rules and measures for preventing and minimizing risks. Although the existence of this legal requirement, the way risk analysis can improve the spatial planning process and impact decision-making is not defined.

With the implementation of the RiskOTe tool within SDSS (hereinafter termed RiskOTe SDSS), three major questions are addressed: (i) which components of a decision support system (and with what characteristics) are required in order to integrate risk mapping?; (ii) can a decision support model be used in risk management to support spatial planning and land-use change assessment?; and (iii) what scenarios can be developed in application of the SDSS?

The implementation of RiskOTe SDSS seeks to demonstrate the advantages associated with land-use decision-making based on a solid foundation of information and analysis on the different hazards, consequences, risks and possible actions that can be taken to mitigate and reduce risks. RiskOTe SDSS fills a gap among the existing tools, based on the following principles: (i) It considers explicitly the risk concept in spatial planning decision-making (integrating hazard and vulnerability components); (ii) It considers preferably the municipal scale for the analysis since different policies are reverted to the territory at this scale; (iii) It considers a "semaphore perspective" in land use transformation, rather than a prohibitionist approach; (iv) It supports decision-making based on a multicriteria approach where the weights are obtained from expert judgements.

This paper first describes, in Section 2, the modelling framework around which RiskOTe SDSS was built, with a special focus on the risk assessment approach, and the land-use transformation model. This section also summarizes the implementation of the SDSS, including the goal, the technological framework and the tool functionalities. Section 3 details the application of RiskOTe SDSS, and the most significant results using the municipality of Oeiras, in Portugal, as a case study. Lastly, Section 4 discusses the limitations of RiskOTe SDSS and the possible challenges in further developments. 


\section{Methods}

\subsection{The Modelling Framework}

\subsubsection{Conceptual Framework}

When assessing the transformation of land-use via integrating the component of analysis of natural and technological risks, it becomes mandatory to adopt a risk concept, since different definitions can be used. The risk concept adopted in the development of RiskOTe SDSS is the probability of harmful consequences, or expected losses resulting from interactions between hazards and vulnerable conditions in a given area $[20,21]$.

$$
\mathrm{R}=\text { Hazard } \times \text { Consequences. }
$$

In the SDSS analysis process (Figure 1) the following phases can be identified: (1) Definition of the area of analysis; (2) Analysis components; (3) Generation and analysis of results; (4) Decision making. The first phase corresponds to the definition of the geographic area in which the scenarios of risk analysis will be applied. The second phase consists of the application of risk analysis models, through a semi-quantitative model and a qualitative model. In this paper, only the semi-quantitative analysis model will be explored.

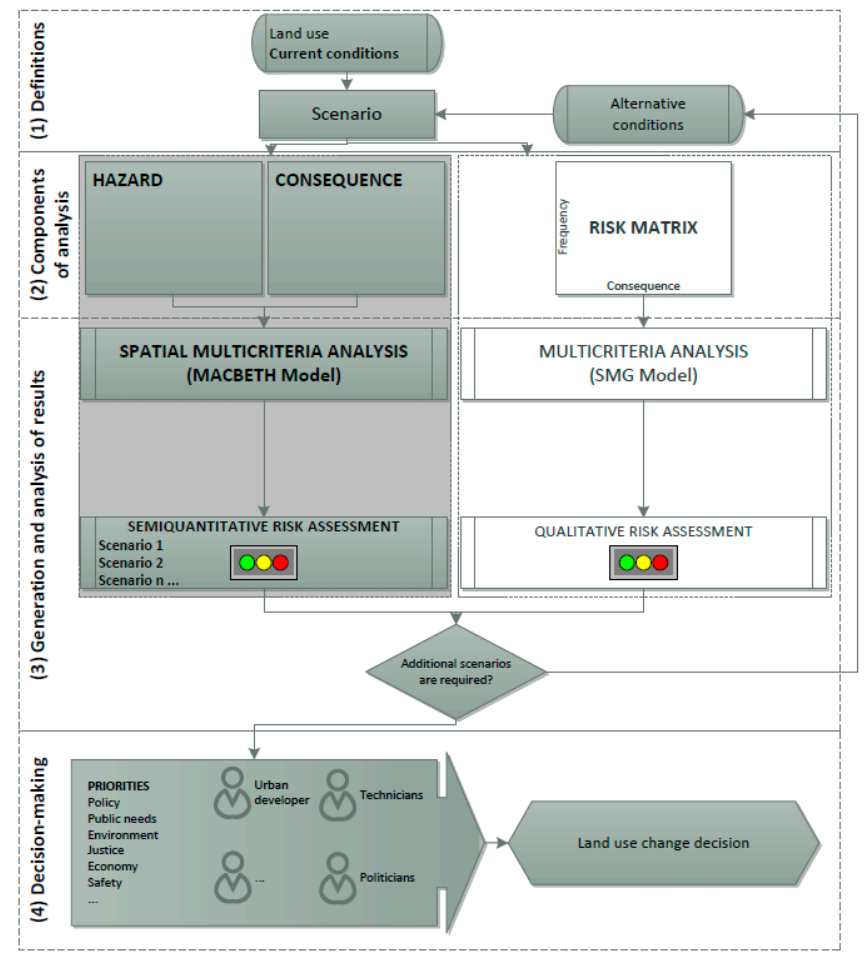

Figure 1. RiskOTe simplified workflow.

The semi-quantitative model expresses the risk in terms of indexes and can be described as a product of a hazard index (HI) by a consequence index (CI), applied to the different hazards that affect spatial planning. The consequence indexes comprise a measure of vulnerability and exposure. The choice of a semi-quantitative approach was due to the difficulty in obtaining vulnerability curves for the different hazards. Figure 2 summarizes the semi-quantitative model for calculating the risk index and can be presented as the product of the hazard index by the consequence indexes for the components of physical, social, economic and environmental vulnerability. This approach is an adaptation of the model presented by Lumbroso and Woolhouse [22]. In terms of weighting 
the different components of vulnerability, the chosen option was based on a multicriteria solution. For the initial default weights, the values were obtained from the MACBETH model $[16,23]$ in order to set the values adapted to Oeiras municipality case study. This methodology was applied in the RiskOTe framework by weighting the four components of consequences (i.e., physical, social, economy, and environment) according to stakeholder preferences.

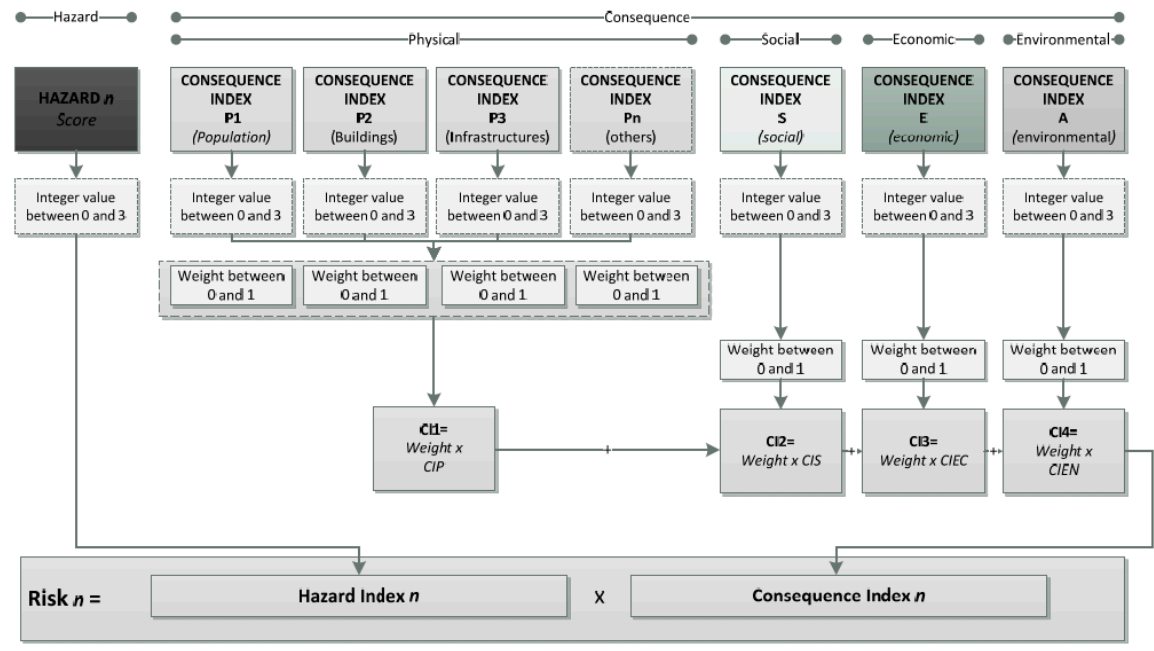

Figure 2. RiskOTe semi-quantitative risk analysis model.

The fourth phase is available through a scenario comparison tool. This tool supports the decision making considering the different perspectives of the stakeholders through different scenarios elaboration and comparison. Although the governance arrangements and power relations often impact processes of plan-implementation and the way urban projects or infra-structures are developed in risk-prone areas, they are not considered in this tool.

\subsubsection{Semi-Quantitative Risk Assessment}

For obtaining the hazard indexes, the classes were based on the methodological guide for the production of municipal risk cartography and for the creation of municipal-based Geographic Information Systems [20], since it was a national guide adopted by all Portuguese municipalities. Table 1 shows the classes used and their reclassification values.

Table 1. Hazard reclassification scheme.

\begin{tabular}{cc}
\hline Class & Index \\
\hline High & 3 \\
Moderate & 2 \\
Low & 1 \\
Null or Non-Applicable & 0 \\
\hline \multicolumn{2}{c}{ Source: RiskOTe. }
\end{tabular}

The development of the consequence indexes is characterized by two fundamental aspects: the vulnerability and the value of the exposed elements. Regarding vulnerability, no curves or functions of vulnerability were used because of their unavailability for all hazards. As an alternative, indexes were calculated for the different vulnerability components considered: (i) Physical; (ii) Social; (iii) Economical; (iv) Environmental.

For the hazards considered in RiskOTe development, different consequence indexes were applied, which include the vulnerability of exposed elements (through an index) and the type and number of exposed elements. 
The physical component of the vulnerability is determined according to the following equation:

$$
C I 1=(C I 11 \times W i)+(C I 12 n \times W j)+(C I 13 \times W k),
$$

where CI11 is the consequence index for population; $W i$ is the weight defined in the RiskOTe scenario; CI12 is the consequence index for buildings considering different hazards; $W j$ is the weight defined in the RiskOTe scenario; CI13 is the consequence index for infrastructures and $W j$ is the weight defined in the RiskOTe scenario.

The physical component of the consequence index has three subcomponents. The first subcomponent is about population and was adapted from Menoni et al. [19]. The population vulnerability is given by:

$$
V I 11=\frac{\operatorname{Pop}(<5)+\operatorname{Pop}(>65)}{\text { Poptot }} \times 100,
$$

where $\operatorname{Pop}(<5)$ is the population under 5 years of age, $\operatorname{Pop}(>65)$ is the population over 65 years of age and Poptot is the total number of residents. The exposure is obtained from the population density. The population consequence sub-index is given by the multiplication of vulnerability by exposure.

The second subcomponent concerns buildings (VI12). The vulnerability of buildings is based on different equations, according to the hazard. The vulnerability of buildings with respect to floods was based on the work of Müller, Reiter and Weiland [24], the vulnerability of buildings with respect to forest fires was based on Caballero, Beltrán and Velasco [25], the vulnerability of buildings with respect to landslides was based on Abella [26], the vulnerability of buildings with respect to coastal erosion was based on Dall'Osso and Dominey-Howes [27], and the vulnerability of buildings with respect to earthquakes was based on Giovinazzi e Lagomarsino [28].

The exposure is obtained from the number of residential and strategic or critical buildings (emergency equipment, social equipment, commercial areas, and hazardous installations). The buildings consequence sub-index (CI12) is given by the multiplication of vulnerability by exposure.

The last subcomponent concerns infrastructures and was adapted from Melis and Maltinti [29] and Jenelius [30]. The vulnerability of infrastructures is given by:

$$
\mathrm{VI13}=W i \times L,
$$

where $W i$ is the weight of the infrastructure typology classes and $L i$ is the length of the infrastructure typology in meters. The consequence index (CI13) results from the sum of the indexes obtained for the different infrastructures considered.

The social component of vulnerability was adapted from Westen et al. [31] and Flanagan et al. [32] and is determined according to the following equation:

$$
\mathrm{VI} 2=(\mathrm{AG}+\mathrm{R}+\mathrm{N}+\mathrm{F}) / 4,
$$

The domain of age and gender (AG) is obtained from the following equation:

$$
\mathrm{AG}=[((\mathrm{P}(0,14)+\mathrm{P}>(65+)) / \mathrm{P}(15,64))+(\mathrm{M} / \mathrm{F})] / 2,
$$

where $\mathrm{P}(0,14)+\mathrm{P}(65+)$ is the sensitive population, $\mathrm{P}(15,64)$ is the active population, $\mathrm{M}$ is the male population and $\mathrm{F}$ is the female population.

The domain of the income $(R)$ is obtained from the following equation:

$$
\mathrm{R}=(\mathrm{PD} / \mathrm{PA}),
$$

where PD corresponds to the unemployed population and PA corresponds to the active population. 
The domain of nationality $(\mathrm{N})$ is obtained from the following equation:

$$
\mathrm{N}=\mathrm{PE} / \mathrm{PT},
$$

where PD corresponds to the foreign population and PT is the total resident population.

The family domain $(\mathrm{F})$ is obtained from the following equation:

$$
\mathrm{F}=\mathrm{FM} / \mathrm{FT} \text {, }
$$

where FM is the number of families with one individual and FT is the total number of families.

The exposure of a statistical area is defined as the total number of residents (IRn). The consequence index $(\mathrm{CI} 2)$ results from the multiplication of the vulnerability index by the exposure:

$$
\mathrm{CI} 2=\mathrm{VI} \times \mathrm{IRn},
$$

The economic vulnerability component is determined from the following equation:

$$
\mathrm{VI} 3=E n / T n,
$$

where En corresponds to the number of establishments in the geographical unit of analysis and Tn corresponds to the total number of establishments in the municipality.

The economic exposure is obtained from the estimated turnover per establishment (EEc).

The consequence index results from the multiplication of the index of vulnerability by exposure:

$$
\mathrm{CI} 3=\mathrm{VI} 3 \times \mathrm{EEc},
$$

The vulnerability of a statistical block was adapted from Léon [33] and is determined from the number of establishments, allowing a fast geographic affectation of the vulnerability, although the number of establishments does not have a direct relation with the economic potential and with the number of jobs.

The environmental vulnerability component, adapted from Sebald [34], is determined from the following equation:

$$
V I 4=(N N+P A) / 2,
$$

where NN corresponds to the proportion of the Natura 2000 sites, a network of nature protection areas established under the 1992 Habitats Directive in the geographical unit of analysis and PA corresponds to the proportion of the protected area / natural park in the geographical unit of analysis.

The exposure component corresponds to the total area of the NATURA 2000 network (NNa) with the total area of the protected area or natural park existing in the municipality ( $\mathrm{APa})$. The consequence index results from the multiplication of the index of vulnerability by the exposure:

$$
\mathrm{CI} 4=\mathrm{VI} 4 \times(\mathrm{NNa}+\mathrm{APa}) .
$$

\subsubsection{Land Use Transformation Model}

The principles of land use transformation were structured according to the different risk classes following the matrix in Figure 3.

The option to use the risk classes reflects the risk concept adopted in RiskOTe SDSS where, in addition to the classical adoption of the hazard classes in spatial planning, the vulnerability component is incorporated using consequence indexes. The other aspect that should be emphasized is the differentiation between urban and rural land in the process of risk assessment, highlighting the preventive character of the matrix. 


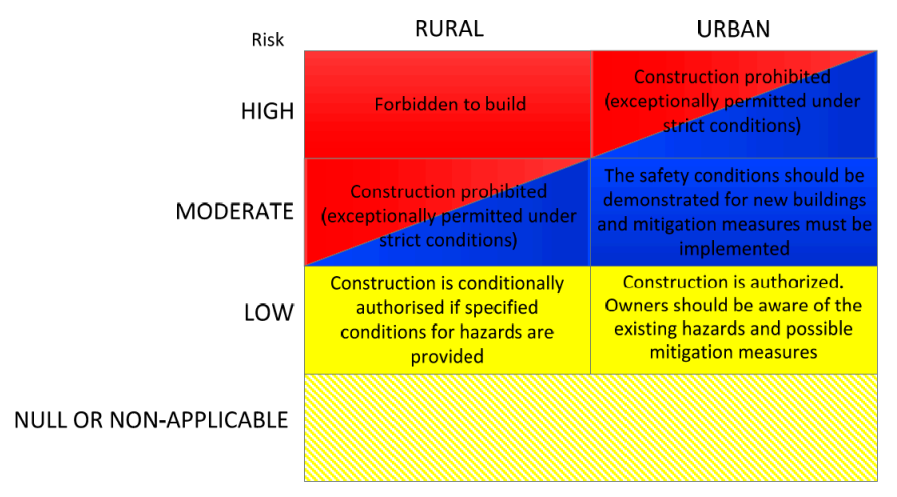

Figure 3. Land use transformation matrix.

\subsection{The Implementation of RiskOTe SDSS}

\subsubsection{Fundamentals of RiskOTe SDSS}

The design and configuration of the decision support system was based on the organization proposed by Sugumaran and DeGroote [8]. The five system components adopted were the following: the knowledge component where the concept of risk is analyzed; the database management component, which describes the alphanumeric tables and layers that are a part of the system; the management component of the model describing the option for the multicriteria analysis in the risk assessment and the land use transformation model; the interface component, which analyses the options and requirements on the interaction channel between users and the system and finally the actors/decision makers component, where risk governance is analyzed.

\subsubsection{Technological Framework}

The RiskOTe technical architecture is organized into three tiers (Figure 4). The "data layer" is responsible for storing and managing the data and is supported on the PostgreSQL database. This is a high-performance relational database management system that includes the PostGIS extension for spatial data storage, adding support for the three characteristics: spatial types, indexes and functions. All the spatial analysis was performed using PostGIS functions.

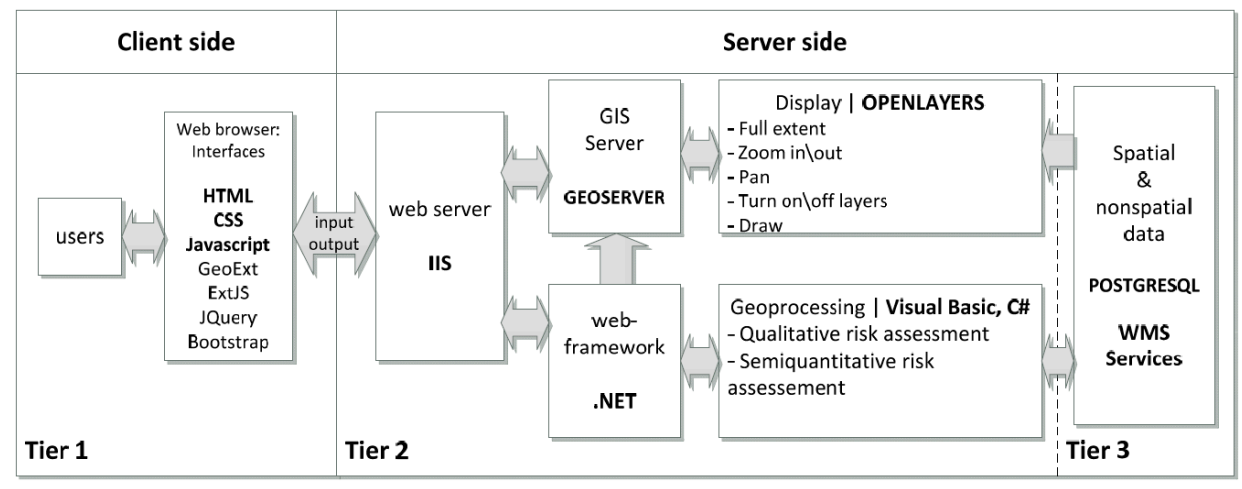

Figure 4. RiskOTe technical architecture.

The "application layer" corresponds to the core of the application and is responsible for controlling its functionalities, as well as having the ability to perform the data transition between the presentation and data layers and to execute all geoprocessing services. This layer integrates the GeoServer map server. GeoServer is an open-source map server written in Java that allows users to share and edit geographic data using open standards defined by the Open Geospatial Consortium (OGC), namely, 
the Web Map Service (WMS) and the Web Feature Service (WFS). The application development was performed using Visual Studio 2013. For the development, the Visual Basic .NET programming language was used as support for the development of all functionalities. The "client layer" or presentation layer is the highest-level layer and is responsible not only for the user/application contact through a set of interfaces that can be presented in a browser, but also for conveying information to the lower layers. This layer was developed in HTML5 and JavaScript, via the use of a set of support libraries such as the OpenLayers JavaScript library for displaying geographic data in browsers, the GeoExt JavaScript library for building web applications with modern interfaces, and other libraries such as Bootstrap and jQuery.

\subsubsection{The Design of the Tool}

In the set-up of the tool, eight steps were considered. These steps are the following: (1) RiskOTE SDSS home page; (2) Multicriteria weighting; (3) Scenario definitions; (4) Hazard analysis; (5) Exposed elements; (6) Analysis of the vulnerability/consequence indexes; (7) Coping capacity; (8) Results and comparison of scenarios.

The first page of the RiskOTe SDSS should be considered as the "knowledge base" and as a gateway to its use (Figure 5a). In the next step, for the four components of the vulnerability, the default weights were obtained from the application of the MACBETH method (Figure 5b). These values can be redefined by the user, depending on the purpose of each scenario. The third step of the RiskOTe decision support system corresponds to definition of the scenario: scenario name, hazards, exposed elements or the layers that integrate mitigation measures (Figure 5c). In this step, it will be necessary to draw a polygon (area to be developed) to be considered in the scenario (Figure 5d). This polygon will be used to make the intersection with the hazards, exposed elements and vulnerability in order to obtain the attributes to be considered in the comparative scenarios.

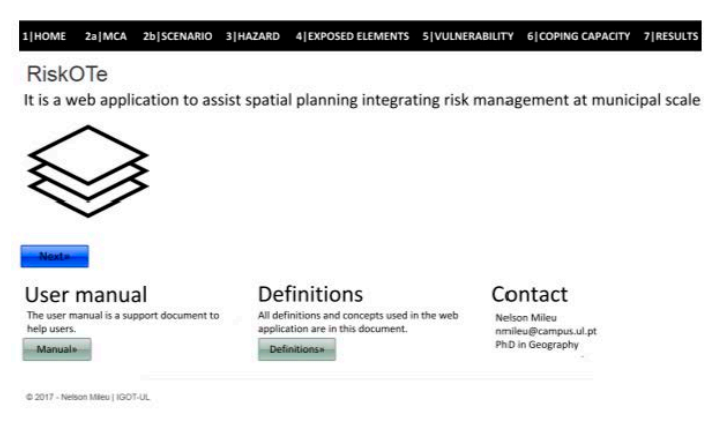

(a)

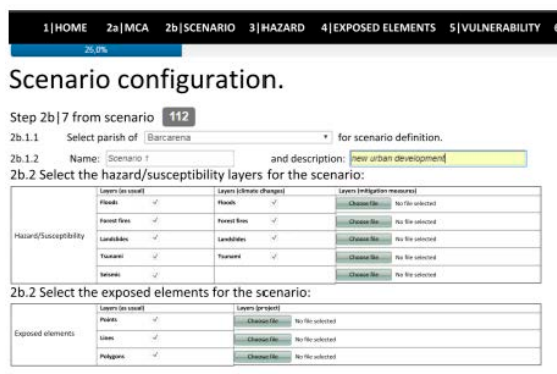

(c)

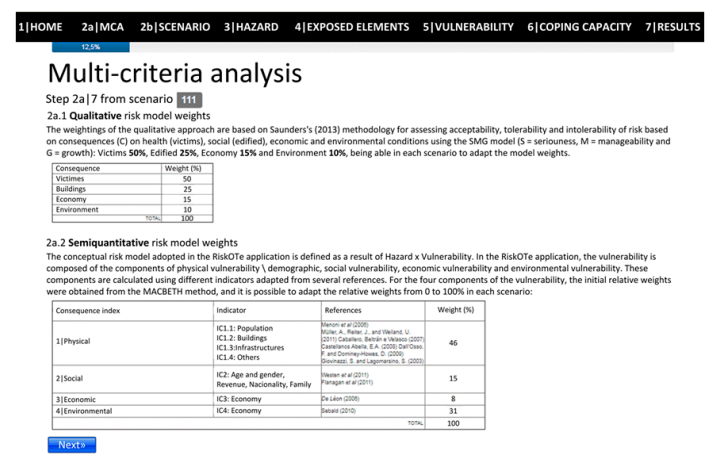

(b)

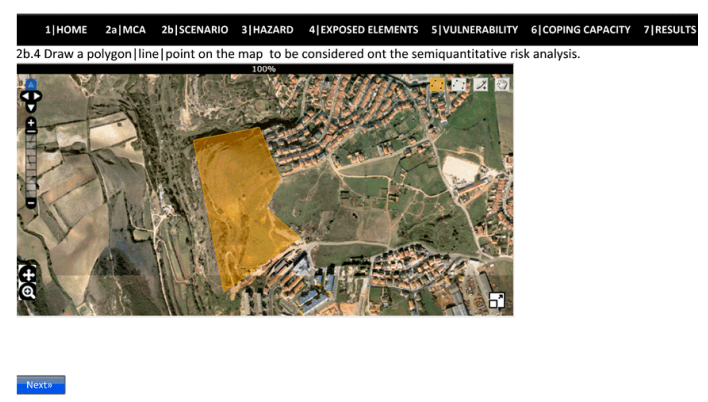

(d)

Figure 5. RiskOTe SDSS first steps: (a) Home page; (b) Multicriteria weighting; (c) Scenario definitions; (d) Location drawing. 
Hazard analysis is accessed in the third step of the decision support system, the scenario configuration. The analyzed layers are the result of the selection made in the previous step, and for each selected hazard a weighted value is calculated as a function of the intersected area that varies between 0 and 3. The exposed elements analysis does not integrate the semi-quantitative risk assessment but is part of the decision support system because it was considered to be an auxiliary element of the knowledge base. In step 5, the calculated maps of consequence indexes for the different vulnerability components are shown. The consequence indexes are structured by the different components of vulnerability analyzed, normalized in a scale of 0 to 3 and are specific for each hazard/risk selected. Although the coping capacity did not integrate the semi-quantitative risk analysis model, it was included in the decision support system as an auxiliary element. The results are presented in the last step of RiskOTe SDSS, and, particularly, the spatial planning recommendations and the comparison of scenarios. This comparison in the last step is available for a better support in the decision-making process.

\section{Case Study}

\subsection{Study Area}

The municipality of Oeiras is the case study that is used to test the applicability of the methodology at municipal level and the implementation of the RiskOTe decision support system. The application of the risk assessment methodology in this case study was related with the level of planning involved and the availability of data.

The municipality of Oeiras is located in the Lisbon Metropolitan Area, Portugal (Figure 6). It is a predominantly urban municipality with a population of 172,120 inhabitants and a high economic development associated with medium-sized and large-sized business locations, mainly associated to higher tertiary activities [35].

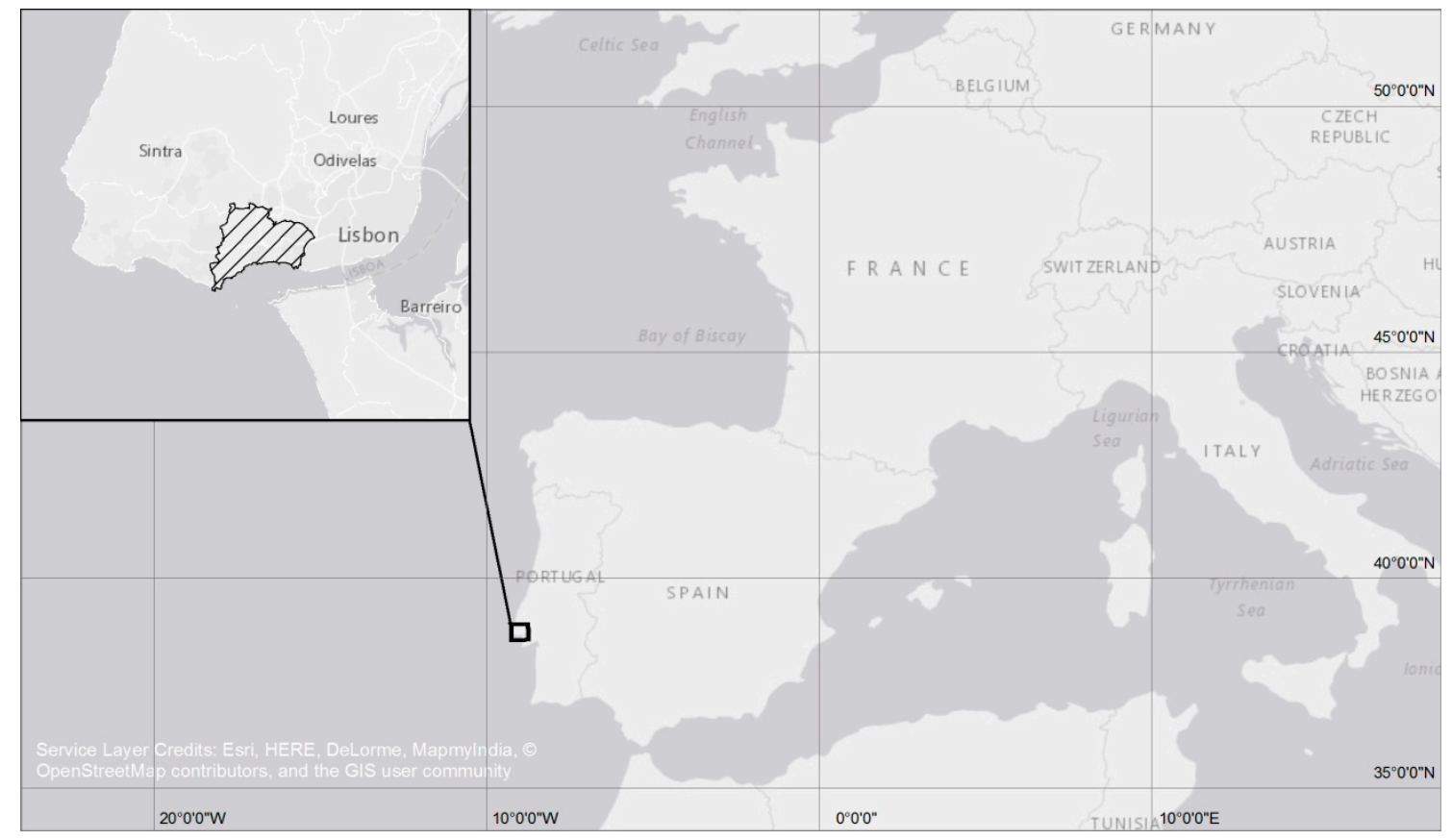

Figure 6. Case study location.

The hazard and consequence index layers used to create the scenarios are described in Table 2. These data are case study-specific and are used in the scenarios depending on the user's initial settings. 
Table 2. Input data synthesis.

\begin{tabular}{|c|c|c|c|c|}
\hline \multicolumn{3}{|c|}{ Risk Components } & Data & Source \\
\hline \multirow{5}{*}{\multicolumn{3}{|c|}{ Hazard indexes }} & Flood hazard & $\begin{array}{l}\text { Oeiras Hydrologic and Hydraulic Flood } \\
\text { Study | Municípia | } 2011\end{array}$ \\
\hline & & & Forest fires susceptibility & $\begin{array}{l}\text { Oeiras Hydrologic and Hydraulic Flood } \\
\text { Study | Municípia | } 2011\end{array}$ \\
\hline & & & Earthquake hazard map & $\begin{array}{l}\text { Oeiras Hydrologic and Hydraulic Flood } \\
\text { Study I Municípia | } 2011\end{array}$ \\
\hline & & & Tsunami susceptibility & $\begin{array}{l}\text { Oeiras Hydrologic and Hydraulic Flood } \\
\text { Study I Municípia | } 2011\end{array}$ \\
\hline & & & Landslides susceptibility & $\begin{array}{l}\text { Oeiras Hydrologic and Hydraulic Flood } \\
\text { Study | Municípia | } 2011\end{array}$ \\
\hline \multirow{6}{*}{ Consequences } & \multirow{3}{*}{ Physical } & Population & Population Census & National Statistical Institute I 2011 \\
\hline & & Buildings & Building inventory & $\begin{array}{l}\text { Oeiras GIS Database | Oeiras } \\
\text { Municipality | } 2011\end{array}$ \\
\hline & & Infrastructures & Infrastructures cadastre & $\begin{array}{l}\text { Oeiras GIS Database | Oeiras } \\
\text { Municipality | } 2011\end{array}$ \\
\hline & \multicolumn{2}{|c|}{ Social } & Population Census & National Statistical Institute | 2011 \\
\hline & \multicolumn{2}{|c|}{ Economical } & $\begin{array}{l}\text { Commerce, services and } \\
\text { equipment survey }\end{array}$ & $\begin{array}{l}\text { Oeiras GIS Database | Oeiras } \\
\text { Municipality | } 2012\end{array}$ \\
\hline & \multicolumn{2}{|c|}{ Environmental } & $\begin{array}{l}\text { Natura Network } 2000 \\
\text { National parks }\end{array}$ & National Forest and Nature Institute \\
\hline
\end{tabular}

All geographic data and auxiliary data used to calculate the consequence indexes were stored in the RiskOTe geographical database. The exposed elements were extracted from the Oeiras municipality 1:2000 cartography and from the Oeiras GIS Database. The 2011 Census of the National Statistics Institute was the main source for the population and buildings data. This option determined the statistical block as the geographic minimum unit for the calculation of the consequence indexes.

\subsection{Scenarios}

The scenarios implemented in RiskOTe SDSS are intended to provide a global view on spatial planning guidelines, considering a semi-quantitative risk analysis. For testing RiskOTe SDSS, three scenarios were developed.

The first exploratory scenario uses the default weights defined by the system. The location of the analysis is in the parish of Porto Salvo and corresponds to the yellow polygon (Figure 7).

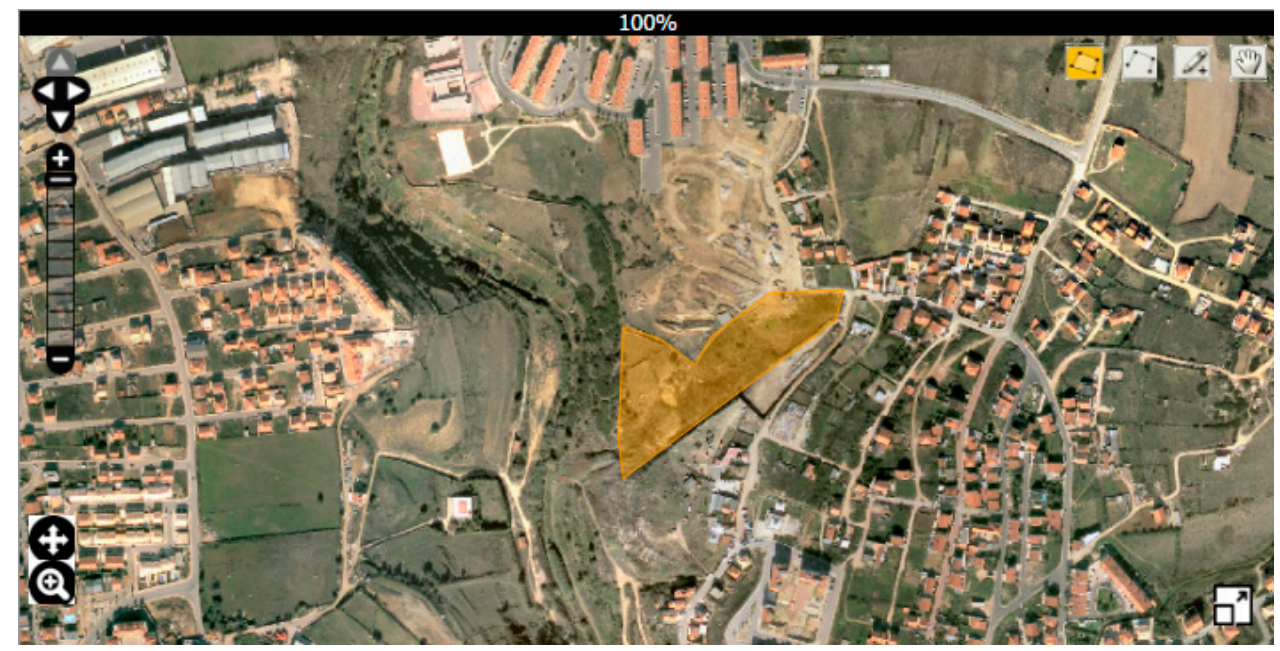

Figure 7. Polygon used in first and second scenario. 
Only bushfires and landslides hazards are intersected with the polygon (Figure 8a), although only the index for bushfires has a high value (2.89). The exposed elements analysis shows that only three linear entities corresponding to local roads are intersected (Figure $8 \mathrm{~b}$ ). The vulnerability analysis shows a low bushfire consequence index (0.92) in the intersected statistical subsection (Figure 8c). With respect to the coping capacity, a distance-time to hospital of 13 to $14 \mathrm{~min}$ and a distance-time from fire station of 6 to 7 min were obtained (Figure $8 \mathrm{~d}$ ).

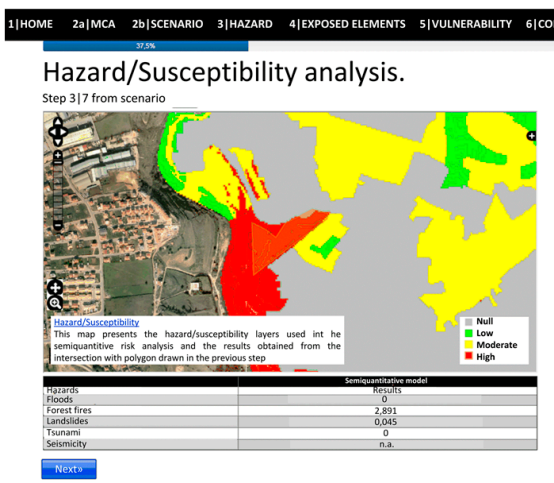

(a)

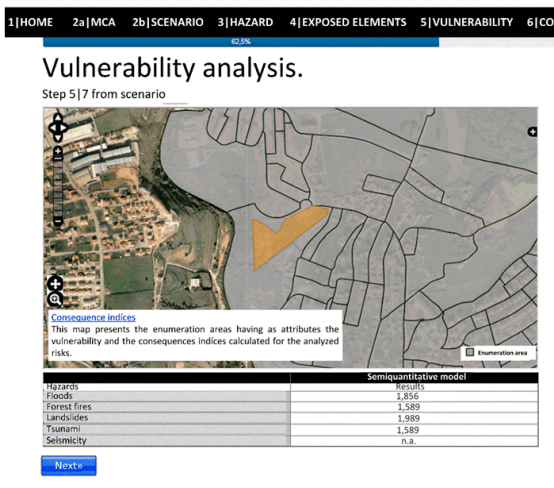

(c)

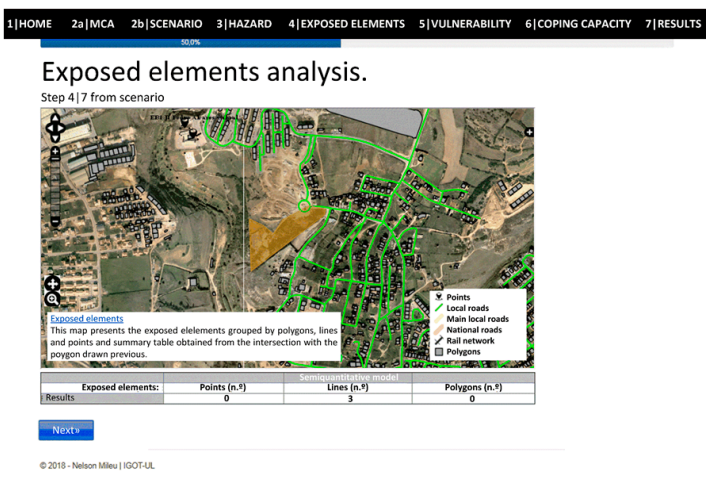

(b)

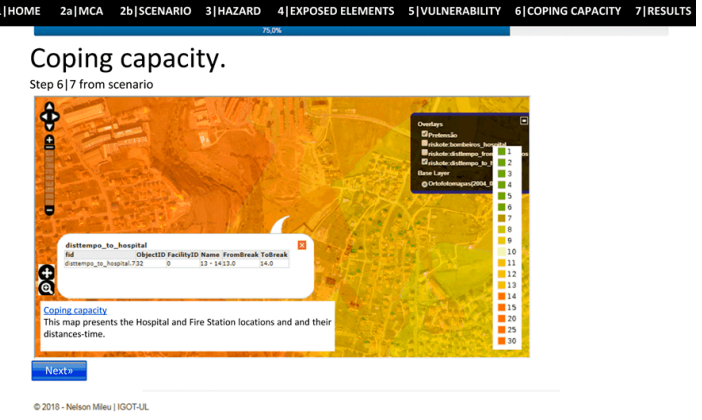

(d)

Figure 8. RiskOTe SDSS analysis steps: (a) Hazard; (b) Exposed elements; (c) Vulnerability/consequence indexes; (d) Coping capacity.

The semi-quantitative risk assessment resulted in a "Low" risk, and an indication for spatial planning where "Construction is authorized. Owners should be aware of existing hazards and possible risk-minimization measures". Despite the high value of the hazard index, the semi-quantitative risk assessment suggests that the model of land-use transformation adopted in the system is not restrictive (Figure 9) in relation to urban development and building.

The second scenario development is based on the previous scenario location and seeks to explore the possibility of introducing a change in the vulnerability component associated with an urban development project. Considering the urban development project hypothesis, the sub-indexes of the physical vulnerability component were updated. For this database update it was considered an increase of 70 residents and 10 buildings in the statistical block. In this scenario, the weights of the multicriteria analysis defined in the base scenario and the location of the analysis were maintained.

Since the polygon location is the same, the same hazards are intersected, corresponding to previous bushfire hazard index (2.89). The exposed elements analysis lists the same three existing local roads. For the vulnerability component, there is an increase corresponding to an index of 1.59 related to the sub-indexes of scenario. With respect to the coping capacity, the response time distances remain the same. 
1|HOME 2a|MCA 2b|SCENARIO 3|HAZARD 4|EXPOSED ELEMENTS 5|VULNERABILITY 6|COPING CAPACITY 7|RESULTS

\section{Results. 目}

Step $7 \mid 7$ from scenario 103

7.1.This table has the results obtained for the current scenario:

\begin{tabular}{|c|c|c|c|c|c|}
\hline & Qualitative model & & Calculated scena & Semi quantit & model \\
\hline Hazards & Risk & Guidance & Hazards & Risk & Guidance \\
\hline Floods & & & Floods & Null & $\begin{array}{l}\text { No restrictions on land } \\
\text { use transformation }\end{array}$ \\
\hline Forest fires & & & Forest fires & Low & 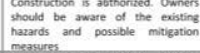 \\
\hline Landslides & & & Landslides & Low & $\begin{array}{l}\text { should be aware of the evisting } \\
\text { havards and possible mitization } \\
\text { mensures }\end{array}$ \\
\hline Tsunami & & & Tsunami & Null & $\begin{array}{l}\text { No restrictions on land } \\
\text { use transformation }\end{array}$ \\
\hline Seismicity & & & Seismicity & - & - \\
\hline
\end{tabular}

7.2. Choose scenario 10 for comparison with current scenario.

Figure 9. Results for the semi-quantitative risk analysis base scenario.

The semi-quantitative risk assessment resulted in a "Moderate" risk, and an indication for the spatial planning in which "the safety conditions must be demonstrated for new buildings and mitigation measures taken". Despite the increase in the value of the consequence index and the consequent change of the semi-quantitative risk assessment, it can be suggested that the model of transformation of the land use adopted in the system is also not very restrictive (Figure 10).

1|HOME 2a|MCA 2b|SCENARIO 3|HAZARD 4|EXPOSED ELEMENTS 5/VULNERABILITY 6|COPING CAPACITY 7|RESULTS

\section{Results. 䕎}

Step $7 \mid 7$ from scenario 104

7.1.This table has the results obtained for the current scenario:

\begin{tabular}{|c|c|c|c|c|c|}
\hline & Qualitative model & & & Semi quantital & model \\
\hline Hazards & Risk & Guidance & Hazards & Risk & Guidance \\
\hline Floods & - & - & Floods & Null & $\begin{array}{c}\text { No restrictions on land } \\
\text { use transformation }\end{array}$ \\
\hline Forest fires & - & - & Forest fires & Moderate & 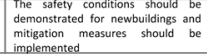 \\
\hline Landslides & - & - & Landslides & Low & 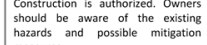 \\
\hline Tsunami & - & - & Tsunami & Null & $\begin{array}{l}\text { No restrictions on land use } \\
\text { transformation }\end{array}$ \\
\hline Seismicity & - & - & Seismicity & - & - \\
\hline
\end{tabular}

7.2. Choose scenario $10 \quad$ for comparison with current scenario.

Figure 10. Results for the semi-quantitative risk analysis base scenario with an increase in the vulnerability component.

The third exploratory scenario corresponds to a different location and uses the default weights defined by the system. The location of the analysis is in the urban area of Oeiras, near the train station and Laje river and corresponds to the yellow polygon (Figure 11).

In this scenario, only the flood extent is intersected by the polygon (Figure 12a), resulting in a high index value (2.98). The exposed elements analysis shows that only one polygon corresponding to a municipal building is intersected (Figure 12b). The vulnerability analysis shows a low flood consequence index (1.26) in the intersected statistical subsection (Figure 12c). With respect to the coping capacity, a distance-time to hospital of 10 to $11 \mathrm{~min}$ and a distance-time from fire station of 1 to 2 min were obtained (Figure 12d). 


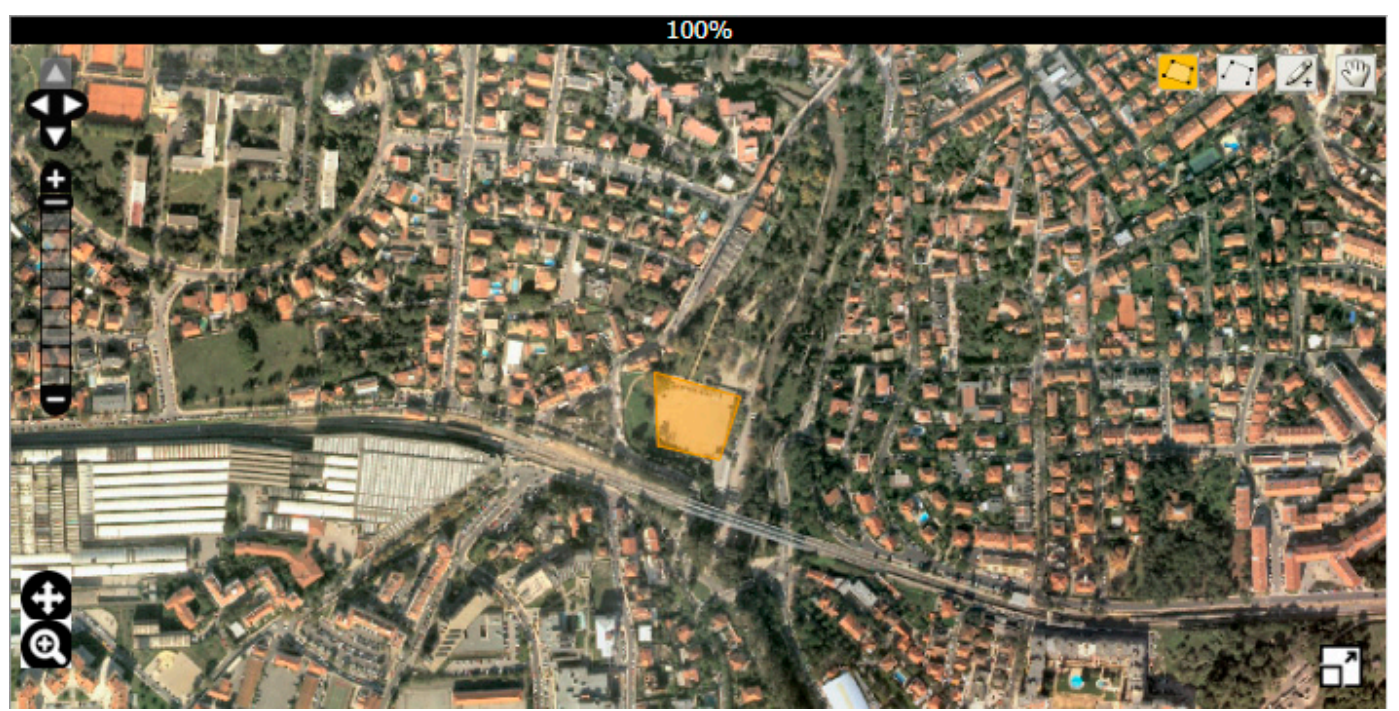

Figure 11. Polygon used in third scenario.

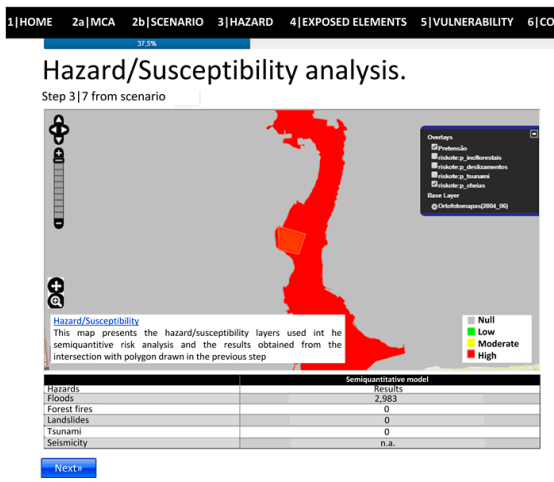

(a)

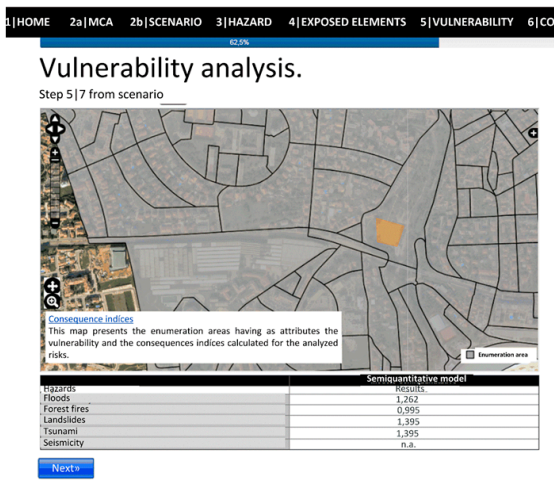

(c)

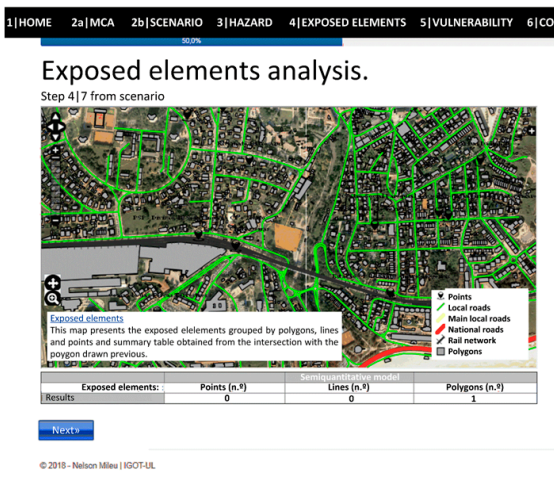

(b)

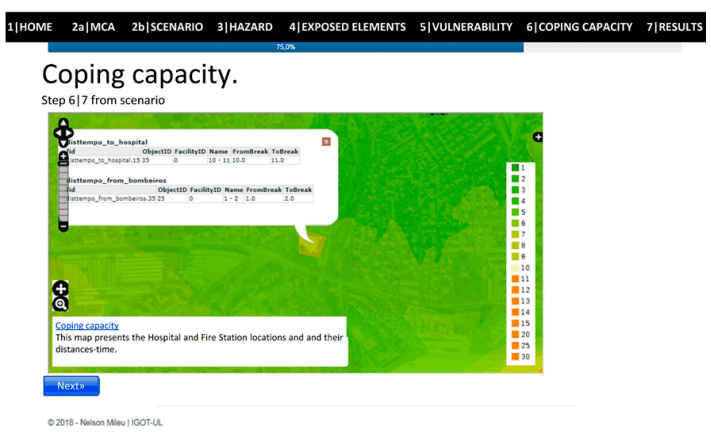

(d)

Figure 12. RiskOTe SDSS analysis steps: (a) Hazard; (b) Exposed elements; (c) Vulnerability/consequence indexes; (d) Coping capacity.

The semi-quantitative risk assessment resulted in a "Moderate" risk, and an indication for the spatial planning in which "the safety conditions must be demonstrated for new buildings and mitigation measures taken" (Figure 13). Since the other hazards do not intersect the polygon there are no restrictions for them. 
1|HOME 2a|MCA 2b|SCENARIO 3|HAZARD 4|EXPOSED ELEMENTS 5/VULNERABILITY 6|COPING CAPACITY 7|RESULTS

\section{Results. 目}

Step $7 \mid 7$ from scenario 116

7.1.This table has the results obtained for the current scenario:

\begin{tabular}{|c|c|c|c|c|c|}
\hline & Qualitative model & & & \multicolumn{2}{|c|}{ Semi quantitative model } \\
\hline Hazards & Risk & Guidance & Hazards & Risk & Guidance \\
\hline Floods & & & Floods & Low & 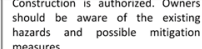 \\
\hline Forest fires & & & Forest fires & Null & $\begin{array}{l}\text { Neasures } \\
\text { No restrictions on land } \\
\text { use transformation }\end{array}$ \\
\hline Landslides & & & Landslides & Null & $\begin{array}{l}\text { No restrictions on land } \\
\text { use transformation }\end{array}$ \\
\hline Tsunami & & & Tsunami & Null & $\begin{array}{l}\text { No restrictions on land } \\
\text { use transformation }\end{array}$ \\
\hline Seismicity & & & Seismicity & - & - \\
\hline
\end{tabular}

7.2. Choose scenario $10 \quad$ for comparison with current scenario.

Figure 13. Results for the semi-quantitative risk analysis scenario on a different location.

\section{Discussion}

The comparative analysis of scenarios demonstrates the applicability of the methodology. The elaboration of the exploratory scenarios made it possible to verify its usefulness, both for present conditions and future conditions and to explore the system analysis, presentation, printing of results, or scenario comparison functionalities.

Additionally, it allowed to identify a set of limitations that can be research perspectives and future developments of the system. Due to the difficulty in obtaining the monetary or strategic value rigorously and the impossibility of general use in all municipalities, the quantification proposed for calculating the consequence index was based on the number of exposed elements. Assuming the limitations of the vulnerability metrics used, the following aspects should be highlighted:

- The integrated use of vulnerability components (physical, social, economic and environmental vulnerability), may be too complex regarding the number of indexes to be calculated and the diversity of variables involved;

- The multicriteria approach for the components of vulnerability considered, despite the advantages [16], is always debatable;

- In all components, the adaptability of variables and weights to regional characteristics is a critical point;

- When calculating indexes for different vulnerability components their use in a composite index constitute problems of comparability;

- When the statistical block is used as the geographical unit of analysis, the problems associated with data aggregation are also a critical point.

Assuming the limitations of the adopted metrics, it should be noted that the flexibility of the system allows the adoption of other metrics, since the resulting indexes are between 0 and 3 . All the indexes were obtained by normalizing the calculated values and by the reclassification through the quantiles method.

The hazard indexes and the consequence indexes based on the vulnerability and exposure of the statistical subsections, either by their origin or by the processes of normalization and classification of the different data associated to the methodology adopted, reveal problems and limitations that must be pointed out. The first limitation to be noted is the lack of data on the population present in the statistical subsections where there are no residential buildings, with particular emphasis on industrial areas, commercial areas or business parks. This limitation is extended to the dynamics and mobility of the present population; hence the methodology does not express daily, weekly or seasonal variations of the population. 
Another issue that is inherent in the choice of the use of the statistical subsections as a geographic unit of analysis is related to the modifiable areal unit problem, usually referred to in the literature as MAUP [36,37], where the resulting summary values are influenced by both the shape and scale of the aggregation unit. The third limitation concerning the RiskOTe SDSS methodology refers to the method of class division used. Although it is an issue that is widely explored and analyzed by several authors [31,38,39], it is important in the context of the development of RiskOTe to emphasize that the use of the quantile method of division into classes is an option with all its advantages and limitations. The last issue is related with the land use transformation model results. The scenarios showed that the model is not very restrictive to land use change, and only when both hazard and vulnerability components have simultaneous high indexes they do result in a restrictive model.

\section{Conclusions}

One of the most relevant aspects of this research is the relevance of the development of a decision support system to support spatial planning which integrates the municipal risk management component. Firstly, it was possible to conceptually define a spatial decision support system to help spatial planning actors in aggregating risk analysis and risk governance using the components of knowledge, model management, database management, interface management and relevant stakeholders. Considering the municipal level as the level where key land-use planning options are assumed to occur, and all risk governance components are in place, the development of the spatial decision support system is preferentially addressed to municipal technicians, with no need for specific knowledge in GIS, providing support to the political decision-making process. With RiskOTe tool it is expected to improve plan-implementation process mainly at the municipal level, supporting the decision-making and helping planning practitioners with better adjusted projects to the context of each territory.

The development of the spatial decision support system was designed for decision making on issues that relate to spatial planning to risk analysis. This development process went beyond the business-as-usual model, and associates risk management with authorization decisions versus prohibition on established cartographic representations of susceptibility and/or hazard, with respect to a model that assumes risk management in a more comprehensive manner according to the type of risk/hazard, vulnerability, coping capacity and risk minimization measures. The results for the different scenarios showed that the land use transformation model based on the risk classification is not very restrictive. Only when the hazard index and the consequence index have simultaneous high values was there an increase in the restrictions to new buildings.

The added value of the risk assessment methodology adopted with RiskOTe is centered on the semi-quantitative model and is related with the layer harmonization and with the calculation of partial and total risk indexes. It should also be noted that the development of indexes as a result of the components of physical, social, economic and environmental vulnerability has proved to be the most complex task from the point of view of implementation. However, given its flexibility, it is the component of the system with potential for evolution. The future development potentials for the tool include the complete migration for an open source environment (using Python and Bottle instead of Visual Basic.NET and Internet Information Services) and the host in GitHub. This migration will allow the use of the tool by other municipalities, although the use of the system by others has a strong dependence on the existence of cartographic data used to calculate the hazard and consequence indexes.

Notwithstanding the limitations associated with the implementation of the system, it was possible to demonstrate the applicability of a spatial decision support system that integrates the concepts associated with risk analysis and risk governance to support decision-making on the transformation of land use. With the implementation of RiskOTe, it is possible to sustain that a decision support system has been conceptually defined, based on a semi-quantitative risk assessment model that allows the elaboration of scenarios that support the decision on the transformation of land use. This tool improves planning practitioners and policy makers. Any municipality can profit from this supportive 
tool. With this approach the process of plan-making and plan-implementation at municipal level can be more effective and adjusted to each territory going beyond the traditional cartographic and GIS approaches.

Author Contributions: All of the authors contributed to this manuscript. N.M. designed and implemented RiskOTe SDSS and wrote the manuscript. M.Q. supported the research as PhD advisor and edited the manuscript.

Acknowledgments: This work was supported by national funds from FCT - Portuguese Foundation for Science and Technology (UID/GEO/00295/2013). The authors acknowledge the reviewers which improved the initial version of this paper. This text presents contributions from Nelson Mileu PhD thesis in Geography, area of specialization in Geographical Information Sciences, with the title "Decision Support System in Municipal Risk Management", elaborated at the Institute of Geography and Spatial Planning of the University of Lisbon (Instituto de Geografia e Ordenamento do Território da Universidade de Lisboa, IGOT-ULisboa) between 2015 and 2016.

Conflicts of Interest: The authors declare no conflict of interest.

\section{References}

1. Newman, J.; Maier, H.; Riddell, G.; Zecchin, A.; Daniell, J.; Schaefer, A.; van Delden, H.; Khazai, B.; O'Flaherty, M.; Newland, C. Review of literature on decision support systems for natural hazard risk reduction: Current status and future research directions. Environ. Model. Softw. 2017, 96, 378-409. [CrossRef]

2. Queirós, M. Riscos e Ordenamento do Território: Prometeus ou conhecimento e partilha. Rev. Cons. Nac. Planeam. Civ. Emerg. 2009, 25, 20-28.

3. Neuvel, J. Geographical Dimensions of Risk Management-The Contribution of Spatial Planning and Geo-ICT to Risk Reduction. Ph.D. Thesis, Wageningen University, Wageningen, The Netherlands, 2009.

4. Schmidt-Thomé, P. Integration of Natural Hazards, Risk and Climate Change into Spatial Planning Practices. Ph.D. Thesis, Helsinki University, Helsinki, Suomi, 2006.

5. Greiving, S.; Fleischhauer, M.; Wanczura, S. Management of Natural Hazards in Europe: The Role of Spatial Planning in Selected EU Member States. J. Environ. Plann. Manag. 2006, 49, 739-757. [CrossRef]

6. Ran, J.; Nedovic-Budic, Z. Integrating spatial planning and flood risk management: A new conceptual framework for the spatially integrated policy infrastructure. Comput. Environ. Urban Syst. 2016, 57, 68-79. [CrossRef]

7. Mileu, N. Integrating Risk Maps in the Definition of Municipal Territorial Models. Finisterra LIII 2018, 107, 51-66.

8. Sugumaran, R.; DeGroote, J. Spatial Decision Support Systems—Principles and Practices; CRC Press, Taylor\&Francis Group: Boca Raton, FL, USA, 2011.

9. Eissa, A. Spatial Decision Support System for Infrastructure Resource allocation. Master's Thesis, University of Twente, Enschede, The Nederlands, 2013.

10. Newman, J.; Maier, H.; Delden, H.; Zecchin, A.; Dandy, G.; Riddel, G.; Newland, C. Literature Review on Decision Support Systems for Optimising Long-Term Natural Hazard Mitigation Policy and Project Portfolios; Report 2014.009; Bushfire and Natural Hazards CRC: Melbourne, Australia, 2014.

11. Belardo, S.; Karwan, K.; Wallace, W. An investigation of system-design considerations for emergency management decision support. IEEE Trans. Syst. Man Cybern. 1984, 14, 795-804. [CrossRef]

12. Belardo, S.; Karwan, K.; Wallace, W. Managing the response to disasters using microcomputers. Interfaces 1984, 14, 29-39. [CrossRef]

13. Wallace, W.; Debalogh, F. Decision support systems for disaster management. Public Adm. Rev. 1985, 45, 134-146. [CrossRef]

14. Cioca, M.; Cioca, L. Decision Support Systems used in Disaster Management. In Decision Support Systems; Jao, S., Ed.; Intech: Rijeka, Croatia, 2010; pp. 371-391. ISBN 978-953-7619-64-0.

15. Cioca, M.; Filip, F. Decision Support Systems-A Bibliography 1947-2007. Available online: http:/ /www.cif. ulbsibiu.ro/mariusc/bibliographySSD.htm (accessed on 30 November 2015).

16. Mileu, N. Sistema de Apoio à Decisão na Gestão do Risco à Escala Municipal. Ph.D. Thesis, University of Lisbon, Lisbon, Portugal, 2016.

17. European Communities (EC). European Spatial Development Perspective; European Communities: Potsdam, Germany, 1999; ISBN 92-828-7658-6. 
18. Applied Multi Risk Mapping of Natural Hazards for Impact Assessment (ARMONIA). A Summary of the Research Undertaken by the ARMONIA Research Project, Funded under the Sixth EU Framework Programme for Research and Technological Development; with Support of T6 Società Cooperativa; Lancaster University, Department of Geography: Lancaster, UK, 2007.

19. Harmonised Hazard, Vulnerability and Risk Assessment Methods Informing Mitigation Strategies Addressing Land-use Planning and Management. Available online: https://forum.eionet.europa.eu/ eionet-air-climate/library/public/2010_citiesproject/interchange/armonia_project/armonia_project_8/ download/en/1/ARMONIA_PROJECT_Deliverable\%205.1.pdf (accessed on 20 March 2018).

20. Julião, R.; Nery, F.; Ribeiro, J.L.; Zêzere, J.L. Guia Metodológico Para a Produção de Cartografia Municipal de Risco e Para a Criação de Sistemas de Informação Geografica (SIG) de Base Municipal; Autoridade Nacional de Proteç̧ão Civil/Direcção Geral de Ordenamento do Território e Desenvolvimento Urbano/Instituto Geográfico Português: Lisboa, Portugal, 2009.

21. UNISDR. Living with Risk. A Global Review of Disaster Reduction Initiatives; United Nations International Strategy for Disaster Reduction: Geneva, Switzerland, 2004; ISBN 9211010640.

22. Implementation of a Case Study Simulation, Armonia Project: Applied Multi-Risk Mapping of Natural Hazards for Impact Assessment. Available online: https://forum.eionet.europa.eu/eionet-air-climate/ library/public/2010_citiesproject/interchange/armonia_project/armonia_project_10/download/en/1/ ARMONIA_PROJECT_Deliverable\%206.1.pdf (accessed on 20 March 2018).

23. Bana e Costa, C.; Corte, J.; Vansnick, J. M-MACBETH Versão 2.4.0 Guia do Utilizador. 2015. Available online: http:/ / www.m-macbeth.com/help/pdf/M-MACBETH\%202.4.0\%20Guia\%20do\%20utilizador.pdf (accessed on 30 November 2015).

24. Müller, A.; Reiter, J.; Weiland, U. Assessment of urban vulnerability towards floods using an indicator-based approach-A case study for Santiago de Chile. Nat. Hazards Earth Syst. Sci. 2011, 11, 2107-2123. [CrossRef]

25. Caballero, D.; Beltrán, I.; Velasco, A. Forest Fires and Wildland-Urban Interface in Spain: Types and Risk Distribution. In Proceedings of the 4th International Wildland Fire Conference, Seville, Spain, 13-17 May 2007.

26. Abella, E. Multi-Scale Landslide Risk Assessment in Cuba. Ph.D. Thesis, University of Utrecht, Utrecht, The Netherlands, 2008.

27. Dall'Osso, F.; Dominey-Howes, D. A Method for Assessing the Vulnerability of Buildings to Catastrophic (Tsunami) Marine Flooding; Sydney Coastal Councils Group Inc.: Sydney, Australia, 2009; p. 138.

28. Giovinazzi, S.; Lagomarsino, S. A Macroseismic Method for the Vulnerability Assessment of Buildings. In Proceedings of the 13th World Conference on Earthquake Engineering, Vancouver, BC, Canada, 27 June 2004; p. 896.

29. Melis, D.; Maltinti, F. Develloping a Vulnerability Index for Road Networks Under Hidrogeological Events. In Proceedings of the 4th Kuhmo-Nectar Conference and Summer School—“Transport and Urban Economics", Copenhagen, Denmark, 29 June-3 July 2009.

30. Jenelius, E. Large-Scale Road Network Vulnerability Analysis. Ph.D. Thesis, Royal Institute of Technology, Stockholm, Sweden, 2010.

31. Van Westen, C.J.; Alkema, D.; Damen, M.; Kerle, N.; Kingma, N. Multi-Hazard Risk Assessment, Distance Education Course; Guide Book; United Nations University-ITC School on Disaster Geoinformation Management (UNU-ITC DGIM): Geneva, Switzerland, 2011.

32. Flanagan, B.; Gregory, E.; Hallisey, E.; Heitgerd, J.; Lewis, B. A Social Vulnerability Index for Disaster Management. J. Homel. Secur. Emerg. Manag. 2011, 8, 3. [CrossRef]

33. Léon, J. Vulnerability-A Conceptual and Methodological Review; Publication Series of United Nations University_Institute for Environment and Human Security (UNU-EHS): Bonn, Germany, 2006.

34. Sebald, C. Towards an Integrated Flood Vulnerability Index-A Flood Vulnerability Assessment. Master's Thesis, University of Twente, Enschede, The Netherlands, 2010.

35. Municípia. Oeiras, Factos e Números-Edição Especial, 1st ed.; Município de Oeiras: Oeiras, Portugal, 2013.

36. Openshaw, S. The Modifiable Areal Unit Problem, Concepts and Techniques in Modern Geography; Geobooks: Norwich, UK, 1983; Volume 38.

37. Mileu, N. Definição Automática de Áreas Censitárias. Master's Thesis, Technical University of Lisbon, Lisbon, Portugal, 2001. 
38. Dias, M. Leitura e Comparação de Mapas Temáticos em Geografia; Memórias do Centro de Estudos Geográficos, 13: Lisboa, Portugal, 1991.

39. Silva, A. Gráficos e Mapas-Representação de Informação Estatística; LIDEL: Lisboa, Portugal, 2006.

(C) 2018 by the authors. Licensee MDPI, Basel, Switzerland. This article is an open access article distributed under the terms and conditions of the Creative Commons Attribution (CC BY) license (http://creativecommons.org/licenses/by/4.0/). 